\title{
Checking the Relationship between Spiritual Intelligence and Enabling in High School Staff in Region 2 of Tehran
}

\author{
Fatemeh Mahzouni ${ }^{1} \&$ Fatemeh Kho'ini $^{2}$ \\ ${ }^{1}$ M. A. Student of Business Administration, Department of Management, Firoozkooh Branch, Islamic Azad \\ University, Firoozkooh, Iran \\ ${ }^{2}$ Ph.D. \& professor, Department of Management, Firoozkooh Branch, Islamic Azad University, Firoozkooh, Iran \\ Correspondence: Fatemeh Mahzouni, Ph.D. \& professor, Department of Management, Firoozkooh Branch, \\ Islamic Azad University, Firoozkooh, Iran. E-mail: fatememahzooni@yahoo.com
}

Received: January 12, 2016

Accepted: February 25, 2016

Online Published: March 18, 2016

doi:10.5539/mas.v10n6p11

URL: http://dx.doi.org/10.5539/mas.v10n6p11

\begin{abstract}
In this study, the relationship between spiritual intelligence and empower in high school staff in region 2 of Tehran is checked. This study sample consisted of 217 people that were selected by random sampling method among high school staff in region 2 of Tehran. For collecting data to test the hypothesis and to test the viewpoints, is used two questionnaires which are made 1) 17-item questionnaire of spiritual intelligence and 2) a questionnaire with 15 items of staff empowerment, which its validity and reliability were confirmed. After collecting the data and required information by the mentioned instruments and particularly through questionnaires, the number of indicators evaluated and information was entered by SPSS software database. In this research hypotheses of research were evaluated and analyzed by statistical analysis according to the questionnaires. It should be noted that for statistical data analysis software SPSS is used. Finally, by evaluation 13 research hypothesis results showed that 13 hypothesis of spiritual intelligence and empowerment of staff in Tehran high schools in Region 2 have a direct connection.
\end{abstract}

Keywords: spiritual intelligence, empowerment, organizational development, high school staff, Tehran

\section{Introduction}

Organizations are always looking to use all possible means to achieve their success. In the past, access to capital investment were taken into account the use of advanced machinery and employ technology to bring the factors as a competitive advantage for the organization, but it is a few years in which the use of people with mental special characteristics and skills issue is highlighted.

With being the complex of organizational environment and accelerating the development and enhancing the competitiveness of organizations, the need for the formation of powerful organizations is essential. Empowerment as an effective means of improving the quality of employees and increasing organizational effectiveness is considered beneficial. Organizations that its employees are work together instead of competing with each other and also help each other in solving complex problems with joint efforts. They love to be given to Partners and prefer collective interests over personal interests. In the empowered organization, employees have implemented a sense of ownership and pride in the innovation and good ideas. In fact, in an environment empowerment is situated an atmosphere in which employees are the main driving force (Ershadi sis and vardini, 2013).

New studies of neurologists show that some brain functions associated with spiritual experience, in such a way that spirituality influences on some parts of the brain (Faramarzi et al., 2009). Attention to spirituality in solving the problems of life, value and meaning of human life began from the time of James (1977) and writing many spiritual experiences. James believed that spirituality makes sense in human life so that human use rational behavior for find meaning in human life, his relationships with others will be a human and believed relationship and has a positive attitude to itself and others. At the beginning of 2000, Zohar and Marshall that was studied in the field of physics, philosophy, and religion, A book which titled Spiritual Intelligence:

Foundation intelligence published that third earnest intelligence was performed as spiritual intelligence in the scientific community. The importance and necessity of the issue of spirituality and religion, especially spiritual 
intelligence, felt from different directions in the new era. One of these requirements in the field of anthropology is attention to the spiritual dimension of man from the perspective of scientists, especially experts of the World Health Organization that recently define human as a biological, psychological, social and spiritual creature (John Smith, 2011).

\section{Theoretical Foundations of Research}

\section{Spiritual Intelligence:}

Zohar and Marshall (2000) have defined spiritual intelligence as an intelligence through which we solve issues of meaning and values, intelligence that place our activities and our lives in the context of a broader, richer and more meaningful, intelligence that helps us understand which actions or any significant way is more meaningful than the other.

\section{Empowering employees:}

Empowerment refers to the process in which the manager helps employees to gain the ability to make independent decisions. This process not only is effectively in performance but also in their character. The most important concept of empowerment is the delegation of authority to the lowest levels of organization (Abtahi and Abbassi, 2007). Spritzer proposed that if empowerment wants to have the necessary performance should be presented before someone does it, the person itself must have felt like this. According to him, an alternative approach helps to enable software instead of hardware perspective. According to him, psychological empowerment is important mental state of the person to his work environment that is something that can be summarized in five feeling, meaningful, competence, effectiveness, their sense of determination and confidence (Spreitzer, 1995).

\section{The main objective:}

The main objective of the study was to investigate the relationship between spiritual intelligence and empower employees of high schools in region 2 of Tehran.

\section{Secondary objectives:}

1. The relationship between existential questioning and empowerment in the employees.

2. The relationship between awareness of the divine presence and empowerment of employees.

3. The relationship between existential questioning and sense of competence among employees.

4. The relationship between existential questioning and the independence of the staff.

5. The relationship between existential questioning and the effectiveness of the staff.

6. The relationship between questioning the existence and significance of the employees.

7. The relationship between existential questioning and trust in employees.

8. The relationship between awareness of the divine presence and sense of competence among employees.

9. The relationship between awareness of the divine presence and independence on the staff.

10. The relationship between awareness of the divine presence and effectiveness of the staff.

11. The relationship between awareness of the divine presence and significance of the employees.

13. The relationship between awareness of the divine presence and trust in employees.

The statistical society

This statistical society study consisted of 217 people that were selected by the random sampling method among school staff in region 2 of Tehran.

\section{Statistical Sample}

This sample size of this study is 217 people, which is selected by simple random sampling method.

\section{The data collection tool}

The most common data collection tool was a questionnaire survey research. For collecting data to test the hypothesis and evaluate the viewpoints, are made by the two questionnaires 1) 17 questionnaire items of spiritual intelligence, 2) 15-item questionnaire of staff empowerment is used which its validity and reliability have been confirmed. Also, in order to complete the necessary information, such as interviews with experts in the field of research was used. The spiritual intelligence questionnaire contains 17 questions which has two subscales of questioning the existence and consciousness of God's presence that questions number 2, 4, 6, 7, 8, 9, 10, 11, 12, 
$14,15,16$ and 17 subscales questioning existence and questions number $1,3,5$ and 13 measures the awareness of the Divine Presence and The questionnaire of empowerment includes 15 questions which includes subscales of competence, independence, effectiveness, significance and confidence that Questions 1, 2 and 3 measure merit and Questions 4, 5 and 6 of measures Independence and questions 7, 8 and 9 measure being effective and questions 10,11 and 12 measures significant and questions 13,14 and 15 measures trust. In This questionnaire study, demographic information is including as the following:

Gender type of respondents: the number of questionnaire respondents according to sex (male and female)

Level of Education: The education level of respondents in terms of (diploma, degree, BA, MA, Ph.D.)

The average age of respondents: status of respondents in terms of age (under 30 years, $40-31$ years,

$50-41$ years, and 50 years later)

Respondents marriage: including the marital status as (single and married)

Respondents work experience includes work experience of the respondents in terms of status (5 years, 5 to 10 years, 10 to 15 years, 15 to 20 years and 20 years later)

Employment Type respondents: employment situation in terms of employment (formal, treaty, contract, etc.).

\section{Validity and reliability}

The purpose of its reliability or validity is that measuring tool can be able to measure the desired characteristic of a measuring tool. In other words, the concept of validity answers the question that measuring tool to what extent can measure the desired characteristic (Sarmad et al., 2006, 170). The face validity of the questionnaire was confirmed by verification experts and professors.

\section{Cranach's alpha}

Reliability of instruments has used the method in measuring the stability and reproducibility of the results. it is The most common methods used in determining the reliability in Cronbach's alpha method that this method is also used in this study. The calculation formula is as follows:

S: total variance

$$
R_{a}=\frac{J}{J-1}\left(1-\frac{\sum s j^{2}}{S^{2}}\right)
$$

$\mathrm{Sj} 2$ : variance of each subset

J2: The number of sub-questionnaire

To determine the reliability of the measurement tool, the Cranach's alpha test method is used. According to $\mathrm{N}$ Nali claims (1978), if Cranach's alpha is greater than 0.7 the result is valid. Therefore, a total number of 30 randomly selected sample questionnaires have been completed and analyzed by spss using Cranach's alpha reliability coefficient of 0.87 was confirmed. The reliability of the questionnaire study is acceptable.

Table 1.

\begin{tabular}{cc}
\hline \multicolumn{2}{c}{ The Cranach's alpha questionnaire results } \\
\hline Cranach's alpha & Number of questions \\
0.87 & 32 \\
\hline
\end{tabular}

\section{Data Analysis Method}

After collecting the data and required information by the listed tools and in particular through questionnaires, the number of indicators evaluated, Information was entered by spss software database. In this study, research hypotheses were evaluated and analyzed by statistical analysis according to the questionnaires. It should be noted that for statistical data analysis software Spss is used. in the description part, at first, the table of the frequency and central tendency (mean), Distribution (SD) standard is calculated and also the relevant diagrams is planned and according to the formulated hypothesis and the implementation of the Kolmogorov - Smirnov test for normality and correlation and regression test using spss software is used to check assumptions.

\section{Inferential statistics}

\section{Check the normality of the variables}

To test Normality and variables, Kolmogorov - Smirnov test was used. 
Table 2. Kolmogorov-Smirnov test

\begin{tabular}{llll}
\hline Variable & Test statistic & The significance level & Result \\
\hline Existential questioning & 1.291 & 0.071 & Normal \\
Awareness of the Divine Presence & 1.031 & 0.238 & Normal \\
Sense of competence & 1.185 & 0.121 & Narmal \\
Independence & 1.025 & 0.244 & Normal \\
Effectiveness & 1.304 & 0.067 & Normal \\
Fignificancy & 1.217 & 0.121 & Normal \\
Staff Confidence & 1.244 & 0.100 & Normal \\
\hline
\end{tabular}

Due to the larger significance level of the test from 0.05 is characterized that all variables are normally distributed.

\section{Check the status of research variables}

A simple t-test was used to evaluate variables. In this section, we first refer to significance level column if this amount is smaller than 0.05 and has a significant difference between the test variable with mean (here 3 ). If the difference with mean, in this case, is positive it shows the upper middle status of varies and if it is negative, indicating the lower-middle status of varies. If the significance level is greater than 0.05 this test is not significant in this variable and has no significant difference with the average range and reflects the state average. In table 3, Central tendency and dispersion of the variables have been reported.

Table 3. Central tendency and dispersion of research variables

\begin{tabular}{cccc}
\hline Research variable & Number & Average & $\begin{array}{c}\text { Standard } \\
\text { deviation }\end{array}$ \\
\hline $\begin{array}{c}\text { Existential questioning } \\
\text { Awareness of the Divine Presence }\end{array}$ & 217 & .32538 & 0.39493 \\
Sense of competence & 217 & 8767.2 & 0.58833 \\
Independence & 217 & 3164.3 & 0.71162 \\
Effectiveness & 217 & 0630.3 & 0.67786 \\
Meaningfulness & 217 & 6851.2 & 0.63802 \\
Staff confidence & 217 & 8635.3 & 0.68660 \\
& & & 0.61048 \\
\hline
\end{tabular}

These reports can also be seen in Figure 1. In this figure, the average scores for each variable reported by according to data by questionnaire.

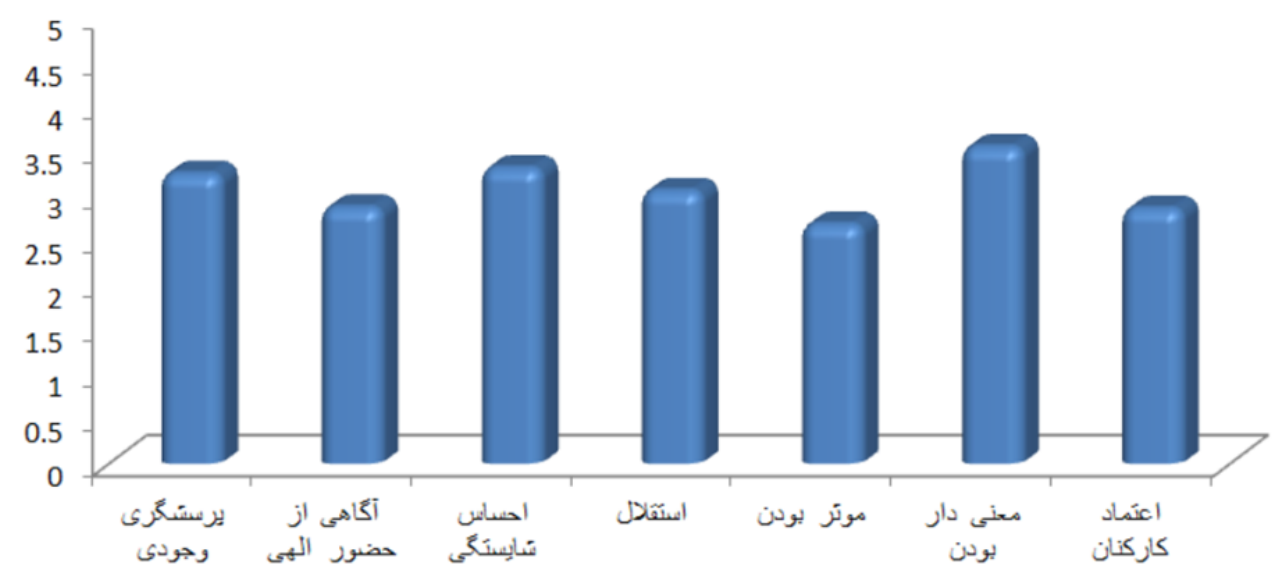

Figure 1. shows the central indicator variables

A simple t-test was used to evaluate variables. 
Table 4. T-test of research variables

\begin{tabular}{lrrrrrr}
\hline Items & \multicolumn{2}{l}{ Test Value $=3$} \\
\cline { 2 - 7 } & T statistic & $\begin{array}{r}\text { Freedom } \\
\text { degree }\end{array}$ & $\begin{array}{r}\text { Significance } \\
\text { level }\end{array}$ & $\begin{array}{r}\text { The average } \\
\text { differences }\end{array}$ & $\begin{array}{r}\text { 95\% confidence } \\
\text { Minimum }\end{array}$ & Maximum \\
\cline { 2 - 7 } Existential questioning & 467.9 & 216 & 0.000 & 0.25381 & 0.2010 & 0.3067 \\
Awareness of the Divine & -087.3 & 216 & 0.002 & -0.12327 & -0.2020 & -0.0446 \\
Presence & & & & & & \\
Sense of competence & 550.6 & 216 & 0.000 & 0.31644 & 0.2212 & 0.4117 \\
Independence & 369.1 & 216 & 0.173 & 0.06298 & -0.0277 & 0.1537 \\
Effectiveness & -271.7 & 216 & 0.000 & -0.31490 & -0.4003 & -0.2295 \\
Having significance & 897.11 & 216 & 0.000 & 0.55453 & 0.4627 & 0.6464 \\
Staff confidence & -299.3 & 216 & 0.001 & -0.13671 & -0.2184 & -0.0550 \\
\hline
\end{tabular}

According to Table 4 specified that the variables of existential questioning, sense of competence, and efficiency and significantly because of being smaller of their significant level from 0.05 and being a positive difference in the average status to above average. Awareness of the divine presence and confidence variables because of being smaller staff due to the significant level of 0.05 and being negative of difference is placed in the average toward low, with the average. Independent variable due to its larger significant level than 0.05 is placed in the middle.

\section{Check the research hypotheses}

The first hypothesis- there is a significant level between the existential questioning and the sense of competence of the staff. In order to evaluate the hypothesis of Pearson correlation test was used. According to the smaller significant level than 0.05 , there is a significant relationship. Also the correlation coefficient of 0.730 is indicative of the changing role of existential questioning in the predictive variables of a sense of competence.

Table 5. The first hypothesis test

\begin{tabular}{lll}
\hline & Pearson correlation & Significant level \\
\hline Existential questioning & 0.730 & 0.000 \\
\hline
\end{tabular}

Due to the positive sign of the coefficients, we can say that the relationship between these two variables is positive. It means that the rise of one is increased another. It will prove according to the results of the above assumptions.

The second hypothesis- there is a significant relationship between existential questioning and independence in staff. In order to evaluate the hypothesis of a test, Pearson correlation test was used. Due to the smaller significance level than 0.05 , there is a significant level. Also, the amount of correlation of 0.708 shows the amount of existential questioning variable in predicting of dependent variable rates.

Table 6. The second hypothesis test

\begin{tabular}{lll}
\hline & Pearson correlation & Significant level \\
\hline Existential questioning & 0.708 & 0.000 \\
\hline
\end{tabular}

Due to the positive sign of the coefficients, we can say that the relationship between these two variables is positive. The rise of one is increased another. it will prove According to the results of the above assumptions.

Third hypothesis- there is a significant relationship between existential questioning and being effective in staff. Pearson correlation test was used to evaluate the hypothesis of being smaller. Due to the smaller significant level than 0.05there is a significant relationship also correlation coefficient of 0.672 doesn't show a significant relationship of amount of existential questioning in predicting effective independent variable. 
Table 7. Third hypothesis testing

\begin{tabular}{lcc}
\hline & Pearson coefficient correlation & Significant level \\
\hline Existential questioning & 0.672 & 0.000 \\
\hline
\end{tabular}

Due to the positive sign of the coefficients, we can say that the relationship between these two variables is positive. The rise of one is increased another. It will prove According to the results of the above assumptions.

Forth hypothesis- there is a significant relationship between existential questioning and being effective in staff. Pearson correlation test was used to evaluate the hypothesis of being smaller. Due to the smaller significant level than 0.05 there is a significant relationship also correlation coefficient of 0.664 doesn't show a significant relationship of amount of existential questioning in predicting effective independent variable.

Table 8. Forth hypothesis testing

\begin{tabular}{lcc}
\hline & Pearson coefficient correlation & significant level \\
\hline existential questioning & 0.664 & 0.000 \\
\hline
\end{tabular}

Due to the positive sign of the coefficients, we can say that the relationship between these two variables is positive. The rise of one is increased another. It will prove According to the results of the above assumptions.

Fifth hypothesis- there is a significant relationship between existential questioning and being effective in staff. Pearson correlation test was used to evaluate the hypothesis of being smaller. Due to the smaller significant level than 0.05 there is a significant relationship also correlation coefficient of 0.620 doesn't show a significant relationship of amount of existential questioning in predicting effective independent variable.

Table 9. Fifth hypothesis testing

\begin{tabular}{lcc}
\hline & Pearson coefficient correlation & significant level \\
\hline existential questioning & 0.620 & 0.000 \\
\hline
\end{tabular}

Due to the positive sign of the coefficients, we can say that the relationship between these two variables is positive. The rise of one is increased another. It will prove According to the results of the above assumptions.

Sixth hypothesis- there is a significant relationship between existential questioning and being effective in staff. Pearson correlation test was used to evaluate the hypothesis of being smaller. Due to the smaller significant level than 0.05 there is a significant relationship also correlation coefficient of 0.641 doesn't show a significant relationship of amount of existential questioning in predicting effective independent variable.

Table 10. Sixth hypothesis testing

\begin{tabular}{lcc}
\hline & Pearson coefficient correlation & significant level \\
\hline god existence & 0.641 & 0.000 \\
\hline
\end{tabular}

Due to the positive sign of the coefficients, we can say that the relationship between these two variables is positive. The rise of one is increased another. It will prove According to the results of the above assumptions.

Seventh hypothesis- there is a significant relationship between awareness of god existence and dependence in staff. Pearson correlation test was used to evaluate the hypothesis of being smaller. Due to the smaller significant level than 0.05 there is a significant relationship also correlation coefficient of 0.685 doesn't show a significant relationship of amount of awareness of god existence role in predicting effective independent variable.

Table 11. Seventh hypothesis testing

\begin{tabular}{lcc}
\hline & Pearson coefficient correlation & significant level \\
\hline god existence & 0.685 & 0.000 \\
\hline
\end{tabular}


Due to the positive sign of the coefficients, we can say that the relationship between these two variables is positive. The rise of one is increased another. It will prove According to the results of the above assumptions.

Eighth hypothesis- there is a significant relationship between awareness of god existence and effectiveness in staff. Pearson correlation test was used to evaluate the hypothesis of being smaller. Due to the smaller significant level than 0.05 there is a significant relationship also correlation coefficient of 0.0 .721 doesn't show a significant relationship of amount of awareness of god existence role in predicting effectiveness variable.

Table 12. Eighth hypothesis testing

\begin{tabular}{lcc}
\hline & Pearson coefficient correlation & significant level \\
\hline god existence & 0.721 & 0.000 \\
\hline
\end{tabular}

Due to the positive sign of the coefficients, we can say that the relationship between these two variables is positive. The rise of one is increased another. it will prove According to the results of the above assumptions.

Ninth hypothesis- there is a significant relationship between awareness of god existence and being significant in staff. Pearson correlation test was used to evaluate the hypothesis of being smaller. Due to the smaller significant level than 0.05 there is a significant relationship also correlation coefficient of 0.640 doesn't show a significant relationship of amount of awareness of god existence role in predicting of significant variable.

Table 13. Ninth hypothesis testing

\begin{tabular}{lcc}
\hline & Pearson coefficient correlation & significant level \\
\hline god existence & 0.640 & 0.000 \\
\hline
\end{tabular}

Due to the positive sign of the coefficients, we can say that the relationship between these two variables is positive. The rise of one is increased another. It will prove According to the results of the above assumptions.

Tenth hypothesis- there is a significant relationship between awareness of god existence and confidence in staff. Pearson correlation test was used to evaluate the hypothesis of being smaller. Due to the smaller significant level than 0.05 there is a significant relationship also correlation coefficient of 0.772 shows a significant relationship of amount of awareness of god existence role in predicting of confidence variable.

Table 14. Tenth hypothesis testing

\begin{tabular}{lcc}
\hline & Pearson coefficient correlation & significant level \\
\hline god existence & 0.772 & 0.000 \\
\hline
\end{tabular}

Due to the positive sign of the coefficients, we can say that the relationship between these two variables is positive. The rise of one is increased another. It will prove According to the results of the above assumptions.

Eleventh hypothesis- there is a significant relationship between awareness of god existence and confidence in staff. Pearson correlation test was used to evaluate the hypothesis of being smaller. Due to the smaller significant level than 0.05 there is a significant relationship also correlation coefficient of 0.720 shows a significant relationship of amount of awareness of god existence role in predicting of independent variable of empowerment.

Table 15. Eleventh hypothesis testing

\begin{tabular}{lcc}
\hline & Pearson coefficient correlation & significant level \\
\hline god existence & 0.720 & 0.000 \\
\hline
\end{tabular}

Due to the positive sign of the coefficients, we can say that the relationship between these two variables is positive. The rise of one is increased another. It will prove According to the results of the above assumptions.

Twelfth hypothesis- there is a significant relationship between existential questioning and empowerment in staff. Pearson correlation test was used to evaluate the hypothesis of being smaller. Due to the smaller significant level 
than 0.05 there is a significant relationship also correlation coefficient of 0.729 shows a significant relationship of amount of existential questioning role in predicting of dependent variable of empowerment.

Table 16. Twelvth hypothesis testing

\begin{tabular}{lcc}
\hline & Pearson coefficient correlation & significant level \\
\hline existential questioning & 0.729 & 0.000 \\
\hline
\end{tabular}

Due to the positive sign of the coefficients, we can say that the relationship between these two variables is positive. The rise of one is increased another. It will prove According to the results of the above assumptions.

Main hypothesis- there is a significant relationship between spiritual intelligence and empowerment in staff. Pearson correlation test was used to evaluate the hypothesis of being smaller. Due to the smaller significant level than 0.05 there is a significant relationship also correlation coefficient of 0.797 shows a significant relationship of amount of spiritual intelligence role in predicting of independent variable of confident.

Table 17. Thirteenth hypothesis testing

\begin{tabular}{lcc}
\hline & Pearson coefficient correlation & significant level \\
\hline spiritual intelligence & 0.797 & 0.000 \\
\hline
\end{tabular}

Due to the positive sign of the coefficients can be said that the relationship between these two variables is positive. It means that the rise of one is increased the other. According to the results of this analysis, the above assumptions will prove.

The first hypothesis- there is a significant relationship between existential questioning and sense of competence in staff. This hypothesis states that there is a direct relationship between staff competence and a sense of existential questioning.

The research findings confirmed this hypothesis with the amount of association of 0.730 and the significant level of less than 0.05 . This result suggests that there is a significant relationship between the existential questioning and sense of competence and as the attention is being asked more the sense of competence of staff will improve. The second hypothesis- there is a significant relationship between existential questioning and independence in staff.

This hypothesis states that there is a direct relationship between existential questioning and the independence of staff. The findings of the research confirmed this hypothesis with the association of 0.708 and the significant level of less than 0.05 .

This result suggests that there is a significant relationship between existential questioning and independence of staff and as pay more attention to existential questioning indicators, the independence of staff is improved.

Hypothesis 3- there is a significant level between existential questioning and the effectiveness of the staff. This hypothesis states that there is a direct relationship between existential questioning and effectiveness of employees. The findings of the research confirmed this hypothesis with the association of 0.672 and the significant level of less than 0.05 . This result suggests that there is a significant relationship between the existential questioning effectiveness of staff and as pay more attention to existential questioning indicators, the effectiveness of staff will improve.

Hypothesis 4. There is a significant relationship between the existential questioning and significance of in staff. This hypothesis states that there is a direct relationship between existential questioning and the significance of the staff. The findings of research confirm this hypothesis by the association of 0.664 and the significant level of less than 0.05 . This result suggests that there is a significant relationship between existential questioning and the significance of staff and as pay more attention to existential questioning indicators, the Significant of staff will improved.

5. Although there is a significant relationship between existential questioning and confidence between in staff. This hypothesis states that there is a direct relationship between existential questioning and confidence in employees. The findings of this research confirmed this hypothesis with the association of 0.620 and a significant level of less than 0.05 . This result suggests that there is a significant relationship between existential questioning and the confidence of staff and as pay more attention to the existential questioning; the sense 
competence in staff will improve.

6. Although there is a significant relationship between god existence and a sense of competence in staff. This hypothesis states that there is a direct relationship between god existence and a sense of competence in employees. The findings of this research confirmed this hypothesis with the association of 0.641 and a significant level of less than 0.05 .This result suggests that there is a significant relationship between god existence and a sense of competence of staff and as pay more attention to the god existence, the sense competence in staff will improve.

7. Although there is a significant relationship between god existence and independence in staff. This hypothesis states that there is a direct relationship between god existence and independence in employees. The findings of this research confirmed this hypothesis with the association of 0.685 and a significant level of less than 0.05 .This result suggests that there is a significant relationship between god existence and independence of staff and as pay more attention to the god existence, the independence in staff will improve.

8. Although there is a significant relationship between god existence and effectiveness in staff. This hypothesis states that there is a direct relationship between god existence and effectiveness in employees. The findings of this research confirmed this hypothesis with the association of 0.721 and a significant level of less than 0.05.This result suggests that there is a significant relationship between god existence and effectiveness of staff and as pay more attention to the god existence, the effectiveness in staff will improve.

9. Although there is a significant relationship between god existence and significance in staff. This hypothesis states that there is a direct relationship between god existence and significance in employees. The findings of this research confirmed this hypothesis with the association of 0.640 and a significant level of less than 0.05.This result suggests that there is a significant relationship between god existence and significance of staff and as pay more attention to the god existence, the significance in staff will improve.

10. Although there is a significant relationship between god existence and confidence in staff. This hypothesis states that there is a direct relationship between god existence and confidence in employees. The findings of this research confirmed this hypothesis with the association of 0.772 and a significant level of less than 0.05.This result suggests that there is a significant relationship between god existence and confidence of staff and as pay more attention to the god existence, the confidence in staff will improve.

11. Although there is a significant relationship between god existence and empowerment in staff. This hypothesis states that there is a direct relationship between god existence and empowerment in employees. The findings of this research confirmed this hypothesis with the association of 0.720 and a significant level of less than 0.05 .This result suggests that there is a significant relationship between god existence and empowerment of staff and as pay more attention to the god existence, the empowerment in staff will improve.

12. Although there is a significant relationship between existential questioning and empowerment in staff. This hypothesis states that there is a direct relationship between existential questioning and empowerment in employees. The findings of this research confirmed this hypothesis with the association of 0.720 and a significant level of less than 0.05 .This result suggests that there is a significant relationship between existential questioning and empowerment of staff and as pay more attention to the existential questioning, the empowerment in staff will improve.

Main hypothesis -There is a significant relationship between spiritual intelligence and empowerment in staff. This hypothesis states that there is a direct relationship between intelligence and empowerment in employees. The findings of this research confirmed this hypothesis with the association of 0.797 and a significant level of less than 0.05.This result suggests that there is a significant relationship between intelligence and empowerment of staff and as pay more attention to the intelligence, the empowerment in staff will improve.

The results of the research with the results of Guidance research (1392) titled as the effect of spiritual intelligence on empowerment of staff in law enforcement of the Western Azerbaijan province. However, in that study, there is no significant correlation between spiritual intelligence and effectiveness. The results of the research with released survey results of Marzabadi (2013) has correlation as organizational spirituality with psychological empowerment, creativity, intelligence, job stress and job satisfaction corresponds University.

\section{Suggestion of Research}

According to a positive and significant relationship in terms of spiritual intelligence and its two components (existential questioning and awareness of god existence) with empowerment of employees to make the empowerment of employees better, including staff competence, independence of staff, staff effectiveness, significance and trust staff offered suggestions for improvement in terms of spiritual intelligence that empower 
employees with improved recovery. Spiritual intelligence and spiritual intelligence structures have been put together, while the search for spirituality, sacred elements, in finding, awareness is high and excellence. Spiritual intelligence is the ability to use such issues that can predict a person's functioning and adaptation and to the production and the valuable results. In this regard, it is suggested to strengthen the spiritual intelligence staff, held training sessions in order to improve its components. Also with the culture of the organization and demonstrate and share the benefits of spiritual intelligence components hidden and implicit in the concept of education played an important role. Religious culture in the organization and presentation patterns can be useful. Therefore, organizational information can be embedded in the places which can be beneficial. Expert meetings, devoted time to promoting spiritual teachings and the creation of incentive mechanisms to promote spiritual intelligence is from other solutions.

\section{References}

Abtahy, S. H., \& Abesy, S. (2007). Empowerment, Karaj, a research institute and management training.

AQayar, C. (2007). Enabling organizations to empower employees, Tehran Sepahan publications.

Arshady, Cis, M., \& Vardini, N. (2013). The effect of spiritual intelligence empowerment law enforcement West Azerbaijan. Journal of Law, 6(12). West Azerbaijan.

Azad, M. E., Hoshmandja, M., \& Pourkhalili, M. (2013). The relationship between organizational spirituality with psychological empowerment, creativity, intelligence, job stress and job satisfaction. Journal of Behavioural Sciences, (2).

Azar, A., \& Rajabzadeh, A. (2002). Practical making decision, Tehran negah danesh.

Faramarzi, S., Homaee, R., Soltan, H. M. (2009). Examine the relationship between intellectual intelligence and emotional intelligence of students, professional traning. Islam and psychological studies, 3(5), 7-23.

Ghorbanzadeh, \& Ome, L. (2013). The impact of spiritual intelligence on the performance of employees in the organization. Journal of Light.

Litchfield, Bruce, Spiritual intelligenc; Illini Christian faculty and staff(1999) www. Uiuc-icfs.orG.

McMullen, B. (2003). Spiritual intelligence. Retrieved from www. Studentbmj.com

Sohrabi, F. (2011). The foundations of spiritual intelligence. Mental Health Journal, 1(1).

Spreitzer, G. M., \& Nason, S. W. A. (1997). Dimensional analysis of the relationship between psychological empowerment and effectiveness: Satisfaction and strain. Journal of Management, 23(2), 19.

Yaghoob, A. (2008). The relationship between spiritual and mental health of college students Bu Ali. Proceedings of the Fourth Seminar mental health.

\section{Copyrights}

Copyright for this article is retained by the author(s), with first publication rights granted to the journal.

This is an open-access article distributed under the terms and conditions of the Creative Commons Attribution license (http://creativecommons.org/licenses/by/3.0/). 